\section{RMD Open}

Rheumatic \&

Musculoskeletal Diseases

\title{
Investigating sirukumab for rheumatoid arthritis: 2-year results from the phase III SIRROUND-D study
}

\author{
Carter Thorne, ${ }^{1}$ Tsutomu Takeuchi, ${ }^{2}$ George Athanasios Karpouzas, ${ }^{3}$ \\ Shihong Sheng, ${ }^{4}$ Regina Kurrasch, ${ }^{5}$ Kaiyin Fei, ${ }^{4}$ Benjamin $\mathrm{Hsu}^{4}$
}

To cite: Thorne C, Takeuchi T, Karpouzas GA, et al. Investigating sirukumab for rheumatoid arthritis: 2-year results from the phase III SIRROUND-D study. RMD Open Published Online First: [please include Day Month Year]. doi:10.1136/ rmdopen-2018-000731

- Prepublication history and additional material for this paper are available online. To view these files, please visit the journal online (http://dx.doi. org/10.1136/rmdopen-2018000731).

This article is based on work previously presented as a poster and oral presentation at the 2017 American College of Rheumatology/Association of Rheumatology Health Professionals Annual Meeting and published as a meeting abstract in 2017.

Received 18 May 2018 Revised 4 September 2018 Accepted 22 September 2018

Check for updates

C Author(s) (or their employer(s)) 2018. Re-use permitted under CC BY-NC. No commercial re-use. See rights and permissions. Published by BMJ.

For numbered affiliations see end of article.

Correspondence to Dr Kaiyin Fei; kfei@its.jnj.com

\section{ABSTRACT}

Objectives The phase III, multicentre, randomised, double-blind, placebo-controlled, parallel-group SIRROUND-D study evaluated long-term efficacy and safety of the interleukin (IL)-6 inhibitor, sirukumab, in patients with active rheumatoid arthritis (RA) refractory to disease-modifying antirheumatic drugs (DMARDs). Methods Patients were randomised 1:1:1 to sirukumab 100 mg every 2 weeks (q2w), 50 mg every 4 weeks or placebo q2w subcutaneously. Patients initially randomised to placebo were rerandomised at Weeks 18,40 or 52 to one of the sirukumab groups until Week 104.

Results of 1670 randomised patients, 1402 were included in the full analysis set and 1269 in the radiographic analysis set at Week 104 . American College of Rheumatology scores, Disease Activity Score based on C-reactive protein, Clinical Disease Activity Index and clinically meaningful improvements in patient-reported outcomes were sustained at Week 104 among patients initially randomised to sirukumab. Placebo patients subsequently rerandomised to sirukumab showed clinical improvements at Week 104 that were comparable to results among patients initially randomised to sirukumab. Radiographic progression from Week 52 to Week 104 was comparable between all groups whether initially randomised to sirukumab or subsequently rerandomised to sirukumab from placebo. No new safety signals were identified in the extended exposure period compared with the initial 52 weeks of treatment.

Conclusions Sirukumab treatment resulted in sustained reductions in clinical signs and symptoms and minimal progression in radiographic damage over 2 years among patients with RA refractory to DMARDs. The safety profile of sirukumab was as expected for an anti-IL-6 agent, with no new signals reported.

\section{INTRODUCTION}

Interleukin (IL)-6 is a cytokine known for its pleiotropic and proinflammatory functions. ${ }^{1}$ The physiological and pathological role of IL-6 is diverse, including differentiation of B cells and T-helper (Th) 17 cells, promoting development of cytotoxic $\mathrm{T}$ cells and macrophage differentiation. ${ }^{2}$ Patients with rheumatoid arthritis (RA) often have
Key messages

What is already known about this subject?

- The efficacy and safety of 6-12 months of treatment with sirukumab, a human monoclonal antibody that inhibits the cytokine interleukin-6 (IL-6), has been reported for three large randomised controlled trials.

What does this study add?

- In a 2-year, phase III clinical trial of sirukumab in rheumatoid arthritis (RA) patients who had inadequate response to disease-modifying antirheumatic drugs (DMARDs), sirukumab treatment demonstrated sustained, long-term efficacy in reducing disease activity, improving patient-reported outcomes and overall function and inhibiting radiographic progression.

- The safety profile of sirukumab was as expected for an anti-IL-6 agent, with no new signals reported in the trial.

How might this impact on clinical practice?

- The results lend support to the effectiveness of biological IL-6 pathway inhibitors as a class of DMARDs in patients with treatment-refractory RA.

increased levels of proinflammatory cytokines such as IL-6, IL-1 and tumour necrosis factor $(\mathrm{TNF})^{3}$ in synovial fluid and serum. Moreover, TNF and IL-1 both can stimulate IL-6 production by multiple cell types in the RA synovium. ${ }^{4}$ Local concentrations of IL- 6 may, in turn, stimulate leucocyte recruitment to the joint, promote osteoclast maturation and activation, potentiate cartilage degradation and stimulate synovial proliferation, contributing to joint damage. ${ }^{56}$ Autoimmune features in RA, such as autoreactive T-cell activation and hypergammaglobulinaemia, may be caused by elevated IL-6 levels. ${ }^{7}$

In both preclinical models of inflammatory arthritis and in patients with RA, IL-6 deficiency or inhibition improves acute disease and results in clinical improvements. ${ }^{2} 8$ Moreover, the effectiveness of the anti-IL-6 
receptor monoclonal antibody (mAb), tocilizumab, in reducing joint swelling and tenderness, improving physical function and reducing the rate of radiographic progression was established in pivotal registration studies. ${ }^{8-12}$

Sirukumab is a human anti-IL-6 mAb that binds with high affinity and specificity to, and inhibits the biological effects of, human IL-6. The 2-year SIRROUND-D study (Clinicaltrials.gov Identifier NCT01604343) was designed to assess efficacy and safety of subcutaneously (SC) administered sirukumab in patients with moderately to severely active RA who were refractory to disease-modifying antirheumatic drugs (DMARDs). Clinical results from SIRROUND-D during the first year of treatment with sirukumab suggested that the compound is safe and effective for patients with RA. ${ }^{13}$ The current report presents results of a range of clinical and radiographic parameters during the second year period from Week 52 to Week 104.

\section{METHODS}

A full study description and methodology for SIRROUND-D are published ${ }^{13}$ and are described briefly here.

This was a global, phase III, randomised, double-blind, placebo-controlled study in patients who were aged 18 years or older, had moderately to severely active RA and were refractory to single-agent or combination DMARD therapy including methotrexate or sulfasalazine. Low-dose oral corticosteroids ( $\leq 10 \mathrm{mg}$ /day of prednisone) and non-biological DMARDs were allowed if the patient was on a stable dose for $\geq 2$ weeks and $\geq 4$ weeks, respectively. Patients previously treated with biologics were permitted in the study if they had not failed anti-TNF or tocilizumab for safety or efficacy reasons and had not received biologics within the past 3 months (6 weeks for etanercept or yisaipu and 4 weeks for anakinra).

Patients were randomised 1:1:1 at Week 0 to treatment with sirukumab $100 \mathrm{mg}$ SC every 2 weeks $(\mathrm{q} 2 \mathrm{w})$, sirukumab $50 \mathrm{mg}$ SC every 4 weeks (q4w) or placebo SC q2w (online supplementary figure $\mathrm{S} 1$ ). ${ }^{13}$

Patients initially randomised to the placebo group were rerandomised 1:1 to receive blinded sirukumab rescue therapy in one of the two sirukumab groups, starting from Week 18 if meeting early escape (EE) criteria $(<20 \%$ improvement from baseline in both swollen and tender joint counts at Week 18), Week 40 if meeting late escape (LE) criteria (did not meet EE criteria and had $<20 \%$ improvement from baseline in both swollen and tender joint counts at Week 40), or Week 52 if patients were still on the placebo treatment, through Week 104. Patients who completed Week 104 and did not enrol into a long-term extension study continued into a safety follow-up period for 16 weeks; therefore, safety data are reported through Week 120.

\section{Assessments}

Efficacy assessments were described previously. ${ }^{13}$ Results in the current report were based on ongoing monitoring of selected efficacy and radiographic parameters assessed between Week 52 and Week 104 for four treatment groups (placebo to sirukumab $100 \mathrm{mg}$ q2w, placebo to sirukumab $50 \mathrm{mg} \mathrm{q} 4 \mathrm{w}$, sirukumab $100 \mathrm{mg}$ q2w and sirukumab $50 \mathrm{mg} \mathrm{q} 4 \mathrm{w})$. Patients in the placebo to sirukumab groups were initially randomised to placebo and either escaped to sirukumab at Week 18 (EE)/Week 40 (LE) or crossed over to sirukumab at Week 52 and continued on sirukumab treatment through Week 104. Patients in the sirukumab $100 \mathrm{mg}$ q2w and $50 \mathrm{mg}$ q4w groups were initially randomised to sirukumab and continued on sirukumab treatment through Week 104. Efficacy was not separately analysed in the EE, LE and crossover groups because of limited subgroup sample size and confounding selection bias in comparing patients who are randomised to treatment, those who escape to treatment and those who never qualify for escape treatment. Non-radiographic parameters included maintenance of American College of Rheumatology (ACR) responses, Disease Activity Score in 28 joints based on C-reactive protein (DAS28 (CRP)) <2.6, Clinical Disease Activity Index (CDAI) remission or low disease activity (defined as $\leq 2.8$ or $\leq 10$, respectively), clinically meaningful improvements in 36-item Short Form Survey (SF-36) physical component summary (PCS) and mental component summary (MCS; defined as a $\geq 5$-point increase) and clinically meaningful improvements in the Health Assessment Questionnaire-Disability Index (HAQDI; defined as a >0.22 unit decrease from baseline).

Radiographic parameters included change from baseline at Week 52 and Week 104 in modified Sharp/van der Heijde score (SHS) for radiographic damage, change from baseline in erosion and joint space narrowing (JSN) score and proportion of patients with radiographic progression, defined as a change from baseline greater than the smallest detectable change (SDC). Radiographic data were from two Read Campaigns. Read Campaign 1 comprised images taken at Week 0 (baseline), Week 18 (for patients who met EE criteria) or Week 24 and Week 52, and analyses were previously reported. ${ }^{13}$ Read Campaign 2 included images taken at baseline, Week 52 and Week 104. Only the data analyses based on Read Campaign 2 are presented in this report, which includes patients who were still on study treatment at Week 52 and who had non-missing SHS scores at both baseline and Week 52 .

The safety assessment was based on reported adverse events (AEs), clinical laboratory tests, vital sign measurements, physical examinations and concomitant medication review.

\section{Statistical methods}

Data were descriptively summarised and no treatment group comparisons were performed. Simple descriptive summary statistics, such as n, mean, SD for continuous variables and counts and percentages for discrete variables were used to summarise most data. 
Demographic and baseline disease characteristics and non-radiographic efficacy endpoints through Week 104 are summarised based on all patients who were randomised into the study and who were still on study treatment at Week 52. The radiographic efficacy endpoints through Week 104 are summarised based on data of Read Campaign 2, including all randomised patients who were still on study treatment at Week 52 and who had non-missing SHS scores at both baseline and Week 52. As Week 52 was the last visit of the placebo-controlled period and first visit of the active-controlled period, all efficacy data at Week 52 were reanalysed in the active-controlled period to provide benchmarks for comparisons with post-Week 52 data. For ACR responses and disease activity measures, non-responder imputation was applied for missing data and treatment failures.

The safety analysis included all patients who received at least one (partial or complete) dose of study agent. Patients were analysed according to the treatment they actually received over the study period.

\section{RESULTS}

\section{Patients}

A total of 1670 patients across 185 sites were randomised, administered at least one dose of study agent and are included in efficacy (non-radiographic) and safety analyses (online supplementary figure S2). Treatment compliance was high (mean $>96 \%$ ) across all treatment groups through Week 104, and $74 \%$ of randomised patients completed 104 weeks of study agent administration. The most common reason for discontinuation of study agent was AEs (11.1\%), followed by withdrawal of consent $(4.5 \%)$ and lack of efficacy $(3.6 \%)$.

Of the 1670 patients randomised at the beginning of the study, a total of 1597 patients received at least one dose of sirukumab and were included in the safety analysis set for sirukumab treatment. The remaining 73 placebo patients were never switched from placebo to sirukumab. At Week 52, a total of 1402 patients remained on study treatment and were included in the efficacy (non-radiographic) analysis set for the active-controlled period from Week 52 to Week $104(\mathrm{n}=458$ placebo, $\mathrm{n}=476$ sirukumab $50 \mathrm{mg} \mathrm{q} 4 \mathrm{w}$ and $\mathrm{n}=468$ sirukumab $100 \mathrm{mg} \mathrm{q} 2 \mathrm{w}$ ); demographic, baseline disease and prior treatment characteristics remained balanced across treatment groups (table 1) and consistent with the full randomised population. ${ }^{13}$ The analysis set for radiographic assessment included 1269 patients $(\mathrm{n}=406$ placebo, $\mathrm{n}=419$ sirukumab $50 \mathrm{mg} \mathrm{q} 4 \mathrm{w}$ and $\mathrm{n}=444$ sirukumab $100 \mathrm{mg} \mathrm{q} 2 \mathrm{w}$ ) who were on study treatment at Week 52 and who had non-missing SHS scores at both baseline and Week 52. A high proportion of patients from the active-controlled analysis had readable X-rays at Week 0 , Week 52 and post-Week 52, ranging from $94.5 \%$ to $97.1 \%$ across the treatment groups.

\section{Non-radiographic efficacy}

Among patients initially randomised to sirukumab, the proportions of patients achieving ACR responses were consistent at Week 52 and Week 104 (figure 1A). Among patients who achieved American College of Rheumatology 20\% (ACR20) and 50\% (ACR50) responses at Week 52, approximately $90 \%$ and $79 \%$, respectively, of patients initially randomised to sirukumab maintained the same response at Week 104 (figure 1B). By Week 104, the placebo crossover groups had similar responses compared with the groups initially randomised to sirukumab.

The proportions of patients who achieved DAS28 (CRP) $<2.6$ at Week 52 and Week 104 are displayed in figure 2A. The proportion of patients achieving DAS28 (CRP) $<2.6$ was consistent at Week 52 and Week 104 among patients initially randomised to sirukumab. Moreover, by Week 104, patients who crossed over from placebo to sirukumab at Week 52 achieved DAS28 (CRP) $<2.6$ at similar rates at Week 104 as patients originally randomised to sirukumab. A consistent proportion of patients in each treatment group sustained DAS28 (CRP) $<2.6$ through Week 104 (figure 2B). The proportions of patients who achieved CDAI remission $(\leq 2.8)$ and low disease activity $(\leq 10)$ were also consistent between Week 52 and Week 104 among patients initially randomised to sirukumab (figure 2C). The proportions of patients who crossed over from placebo to sirukumab at Week 52 and achieved CDAI remission or low disease activity increased between Week 52 and Week 104, ultimately reaching levels comparable to those among patients originally randomised to sirukumab.

Figure 3 displays results from patient-reported outcomes, including SF-36 PCS and MCS, and the HAQ-DI. The proportions of patients who achieved clinically meaningful improvements in SF-36 MCS scores were similar at Week 52 and Week 104 among all treatment groups, while the proportions of patients who achieved clinically meaningful improvement in PCS scores increased in all treatment groups from Week 52 to Week 104 (figure 3A). Similar results were observed when assessing clinically meaningful improvement according to HAQ-DI scores. Specifically, the proportions of patients who achieved a HAQ-DI response at Week 52 were maintained through Week 104 in groups originally randomised to sirukumab (figure $3 \mathrm{~B}$ ), while proportions of patients who achieved a HAQ-DI response in the placebo crossover groups at Week 104 were comparable to patients initially randomised to sirukumab. The proportion of patients who achieved a HAQ-DI response from Week 52 to Week 104 increased among patients who crossed over from placebo to sirukumab $100 \mathrm{mg} \mathrm{q} 2 \mathrm{w}$.

\section{Radiographic endpoints}

Mean changes from baseline in SHS at Week 52 and Week 104 are presented in figure 4A and summarised in online supplementary table S1. Mean changes from baseline remained below the SDC for SHS among patients originally randomised to sirukumab (online supplementary table S1), and mean changes in SHS from Week 52 
Table 1 Demographic and baseline characteristics (efficacy analysis set; active-controlled period) ${ }^{\star}$

\begin{tabular}{|c|c|c|c|c|}
\hline Characteristics & $\begin{array}{l}\text { Placebo to } \\
\text { sirukumab } \\
50 \text { mg q4w } \\
(n=226+)\end{array}$ & $\begin{array}{l}\text { Placebo to } \\
\text { sirukumab } \\
100 \mathrm{mg} \text { q2w } \\
(\mathrm{n}=232)\end{array}$ & $\begin{array}{l}\text { Sirukumab } \\
50 \mathrm{mg} \mathrm{q4w} \\
(\mathrm{n}=476 \neq)\end{array}$ & $\begin{array}{l}\text { Sirukumab } \\
100 \text { mg q2w } \\
\text { ( } n=468 \ddagger)\end{array}$ \\
\hline Female sex, $n(\%)$ & $169(74.8)$ & $187(80.6)$ & $384(80.7)$ & $380(81.2)$ \\
\hline Age, years & $52.8(11.9)$ & $52.2(11.8)$ & $52.7(11.6)$ & $52.7(11.0)$ \\
\hline \multicolumn{5}{|l|}{ Race, n (\%) } \\
\hline White & $170(75.2)$ & $161(69.4)$ & $334(70.2)$ & $339(72.4)$ \\
\hline Asian & $32(14.2)$ & $37(15.9)$ & $78(16.4)$ & $81(17.3)$ \\
\hline Black or African American & $5(2.2)$ & $10(4.3)$ & $12(2.5)$ & $9(1.9)$ \\
\hline American Indian or Alaska Native & $4(1.8)$ & $2(0.9)$ & $3(0.6)$ & $4(0.9)$ \\
\hline Other§ & $14(6.2)$ & $20(8.6)$ & $46(9.7)$ & $33(7.1)$ \\
\hline Not reported/unknown & $1(0.4)$ & $2(0.9)$ & $2(0.4)$ & $2(0.4)$ \\
\hline Weight, kg & $73.2(17.2)$ & $71.9(16.3)$ & $72.4(18.7)$ & $70.9(16.2)$ \\
\hline Disease duration, years & $8.1(7.0)$ & $7.9(6.8)$ & $8.8(7.7)$ & $8.5(7.1)$ \\
\hline $\mathrm{BMI}, \mathrm{kg} / \mathrm{m}^{2}$ & $27.4(6.0)$ & $27.0(5.6)$ & $27.4(6.5)$ & $26.8(5.6)$ \\
\hline $\mathrm{CRP}, \mathrm{mg} / \mathrm{dL}$ & $2.9(4.5)$ & $2.4(2.5)$ & $2.3(2.4)$ & $2.3(2.4)$ \\
\hline RF positive, n (\%) & $173(76.9)$ & $188(81.0)$ & $370(78.1)$ & $394(84.4)$ \\
\hline Anti-CCP positive, $n(\%)$ & $189(83.6)$ & $201(87.0)$ & $410(86.1)$ & $409(87.8)$ \\
\hline HAQ-DI score, range: 0-3 & $1.54(0.65)$ & $1.55(0.65)$ & $1.50(0.61)$ & $1.51(0.66)$ \\
\hline DAS28 (CRP) & $6.0(1.0)$ & $5.9(0.9)$ & $5.9(0.9)$ & $5.8(0.9)$ \\
\hline CDAl score & $39.94(12.15)$ & $39.17(12.18)$ & $38.79(12.49)$ & $37.55(11.83)$ \\
\hline Concomitant MTX use, $\mathrm{n}(\%)$ & $201(88.9)$ & $203(87.5)$ & $425(89.3)$ & $409(87.4)$ \\
\hline
\end{tabular}

*Values are mean (SD) unless otherwise indicated. Data are shown for the active-controlled efficacy population, which included patients who reached Week 52 and entered into the blinded active treatment phase of the study.

†At Week 52, one patient initially randomised to placebo was rerandomised to sirukumab $50 \mathrm{mg} \mathrm{q} 4 \mathrm{w}$, but discontinued treatment and never received sirukumab treatment.

‡Five patients who continued treatment in the sirukumab $50 \mathrm{mg} \mathrm{q} 4 \mathrm{w}$ group at Week 52 and two patients who continued treatment in the sirukumab $100 \mathrm{mg}$ q2w group at Week 52 were not eligible for inclusion in active-controlled efficacy population (Week 52 to Week 104). $\S N o$ native Hawaiian or other Pacific Islanders were reported in any treatment group.

BMI, body mass index; CCP, cyclic citrullinated peptide; CDAI, Clinical Disease Activity Index; CRP, C-reactive protein; DAS28 (CRP), Disease Activity Score in 28 joints based on CRP; HAQ-DI, Health Assessment Questionnaire-Disability Index; MTX, methotrexate; RF, rheumatoid factor; q2w, every 2 weeks; q4w, every 4 weeks.

to Week 104 were generally negligible across all treatment groups, regardless of whether patients were randomised to placebo and rerandomised to sirukumab at Weeks 18 (EE) /40 (LE) /52 (crossover) or were initially randomised to sirukumab (online supplementary table S2). Probability plots of change from baseline in SHS score at Week 52 and Week 104 are shown in figure 4B. At Week 52 and Week 104 , the proportions of patients with radiographic progression based on SHS were similar for both doses among those initially randomised to sirukumab (online supplementary table S1). At Week 104, a greater inhibition of radiographic progression was observed in the sirukumab $50 \mathrm{mg} \mathrm{q} 4 \mathrm{w}$ and $100 \mathrm{mg} \mathrm{q} 2 \mathrm{w}$ groups compared with the placebo crossover groups, although the disparity at Week 104 is less than the disparity at Week 52.

At Week 52 and Week 104, the proportions of patients with changes in SHS $\leq 0$ were generally comparable for both doses of sirukumab among patients initially randomised to sirukumab (online supplementary table S1) and for both doses among placebo patients who were rerandomised to sirukumab (online supplementary table S3). Mean changes in erosion and JSN scores between Week 52 and Week 104 were generally negligible for all patients, regardless of whether they were rerandomised from placebo to sirukumab or were initially randomised to sirukumab (online supplementary table S2).

\section{Safety}

The overall safety profile of sirukumab $50 \mathrm{mg} \mathrm{q} 4 \mathrm{w}$ and 100 mg q2w in patients with active RA did not change through Week 120 compared with Week 52 results, ${ }^{13}$ and no new safety signals were identified in the extended exposure period. Overall, through Week 120, AEs and serious AEs (SAEs) were reported in similar proportions of patients in the sirukumab $50 \mathrm{mg} \mathrm{q} 4 \mathrm{w}$ combined $(84.0 \%$ and $17.7 \%$, respectively) and sirukumab $100 \mathrm{mg} \mathrm{q} 2 \mathrm{w}$ combined $(86.7 \%$ and $16.5 \%$, respectively) groups (table 2 ). No dose relationship was apparent between the sirukumab dose regimens 
A. Placebo to Sir $50(\mathrm{n}=226) \quad$ Placebo to $\operatorname{Sir} 100(\mathrm{n}=232) \quad$ Sir $50(\mathrm{n}=476) \quad$ Sir $100(\mathrm{n}=468)$

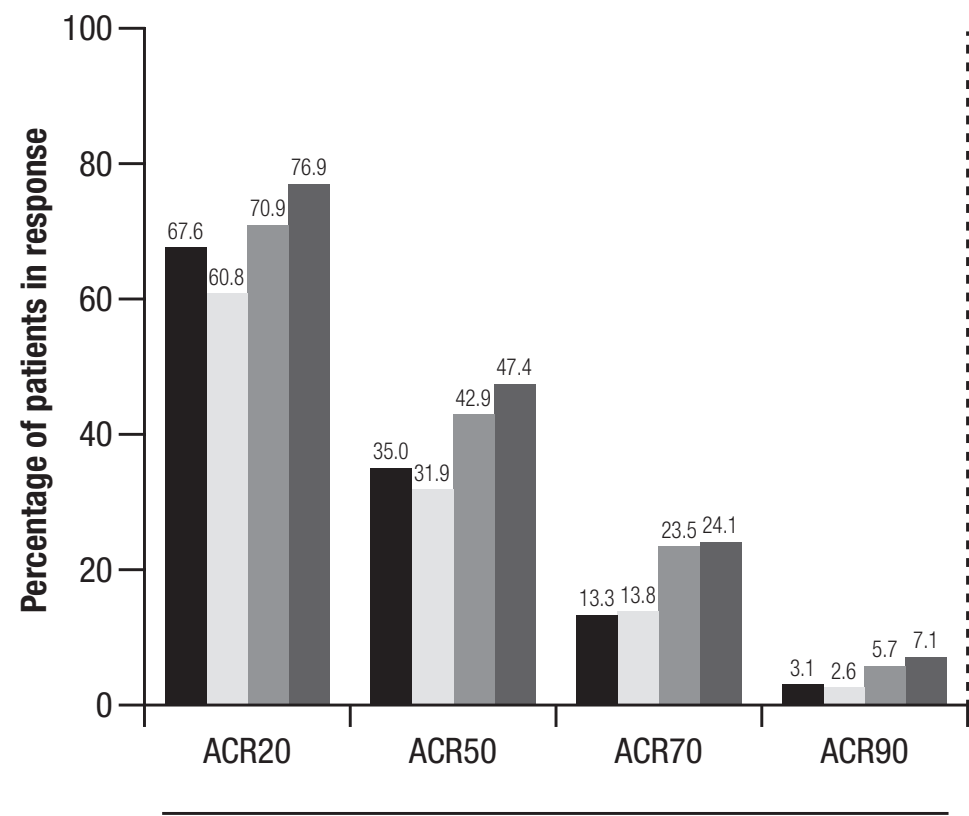

Week 52

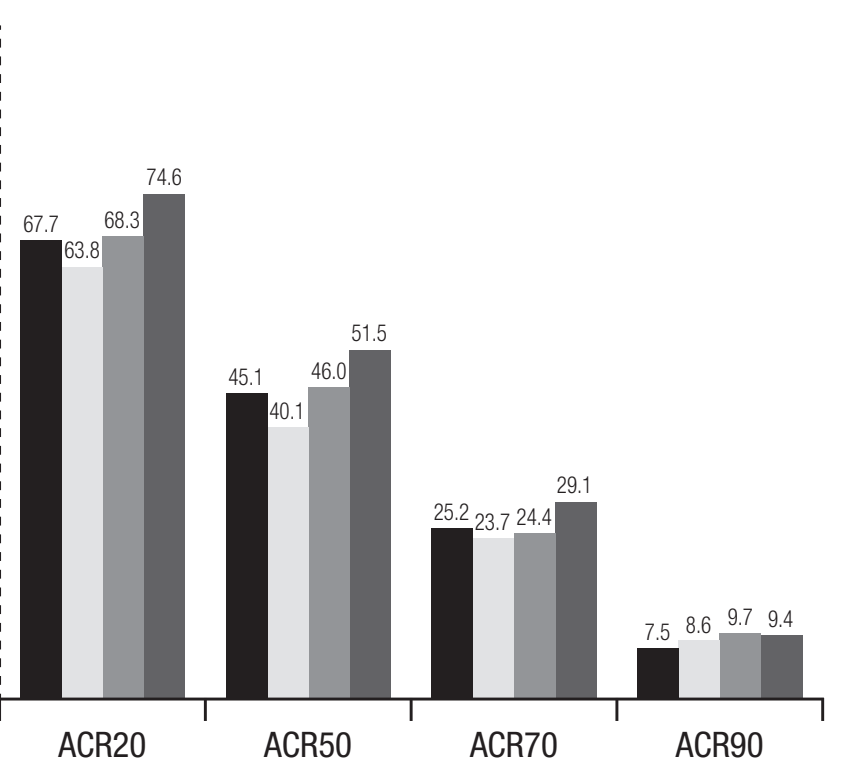

Week 104

B.

Placebo to Sir $50(n=226)$

Placebo to Sir $100(n=232)$

Sir $50(n=476)$

Sir $100(n=468)$

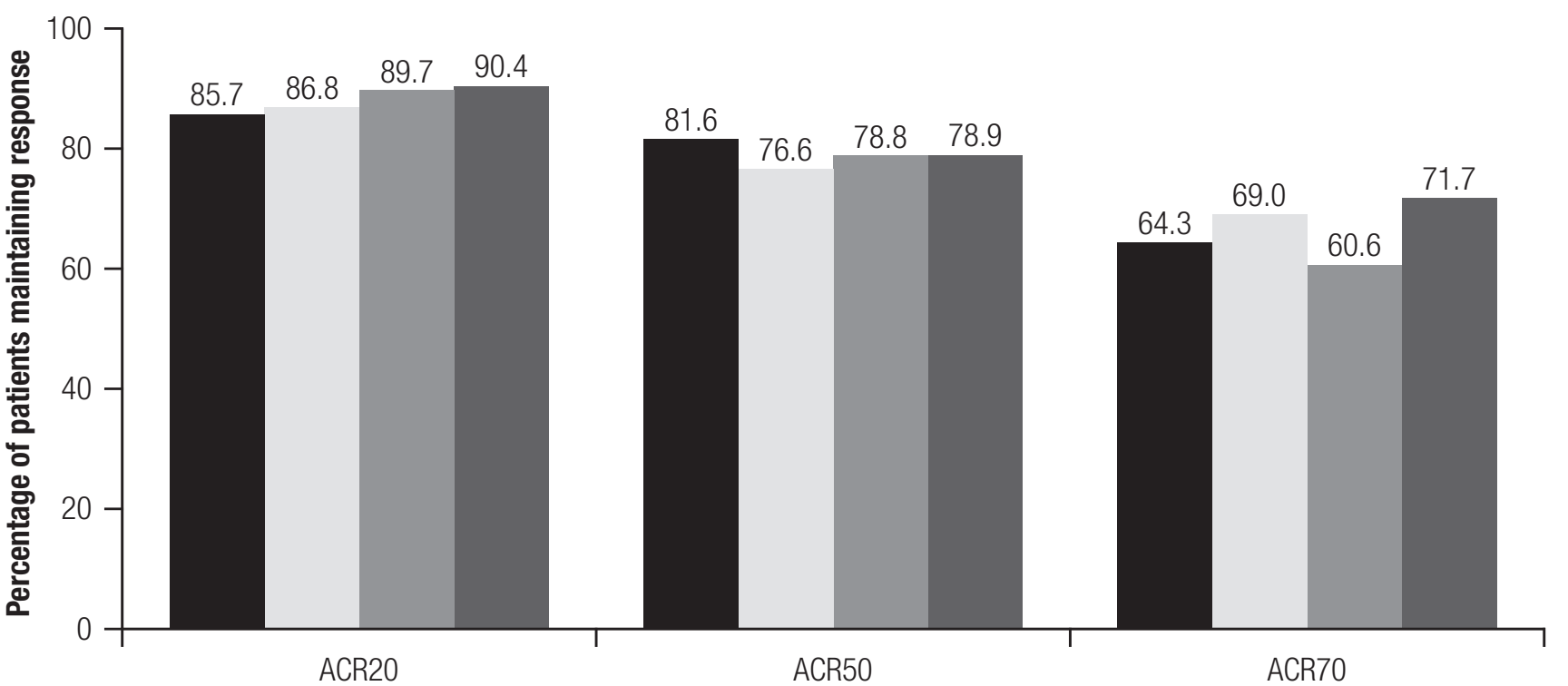

Figure 1 ACR responses: (A) responses at Week 52 and Week 104* †‡; (B) maintenance of response from Week 52 to Week $104 \S$. ${ }^{*} n$ values shown in legend are the number of patients evaluable at Week 52. Responses at Week 52 included EE/LE and CO patients. †For ACR20 and ACR90, placebo to Sir $50 \mathrm{mg} \mathrm{q4w}, \mathrm{n}=225$; placebo to Sir $100 \mathrm{mg}$ q2w, $\mathrm{n}=232$; Sir $50 \mathrm{mg}$ q4w, $\mathrm{n}=475$; Sir $100 \mathrm{mg} \mathrm{q2w}, \mathrm{n}=468$. $\ddagger A C R$ response was based on imputed value by missing data (NR)/TF(NR). $\S A C R$ response was based on observed data. ACR20/ACR50/ACR70/ACR90, American College of Rheumatology 20\%/50\%/70\%/90\% response; CO, crossover; EE, early escape; LE, late escape; NR, non-responder; Sir, sirukumab; TF, treatment failure; q2w, every 2 weeks; q4w, every 4 weeks.

and the types or frequencies of AEs, with the exception of injection site reactions, which occurred in a higher number of patients treated with sirukumab $100 \mathrm{mg} \mathrm{q} 2 \mathrm{w}(16.9 \%)$ vs sirukumab $50 \mathrm{mg} \mathrm{q} 4 \mathrm{w}(10.5 \%)$. The most common injection site reactions were injection site erythema, injection site pruritus and injection site swelling; yet, no patient had a serious injection site reaction. The occurrence of serious or moderate/severe and systemic hypersensitivity reactions was low. Seven patients reported hypersensitivity reactions, with two in the placebo group, two in the sirukumab $50 \mathrm{mg}$ $\mathrm{q} 4 \mathrm{w}$ combined group and three in the sirukumab $100 \mathrm{mg}$ $\mathrm{q} 2 \mathrm{w}$ combined group. No serum sickness or anaphylaxis 
A.

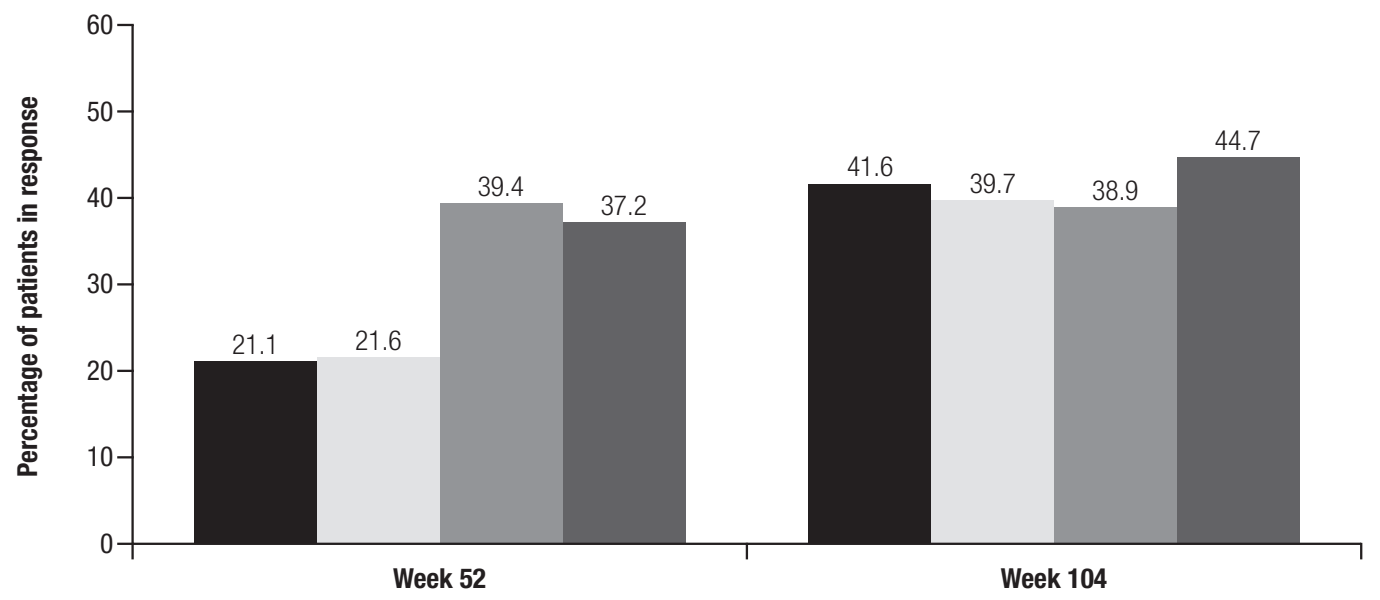

B. $\quad$ Placebo to $\operatorname{Sir} 50(\mathrm{n}=42) \square$ Placebo to $\operatorname{Sir} 100(\mathrm{n}=43) \quad \operatorname{Sir} 50(\mathrm{n}=172) \quad$ Sir $100(\mathrm{n}=161)$
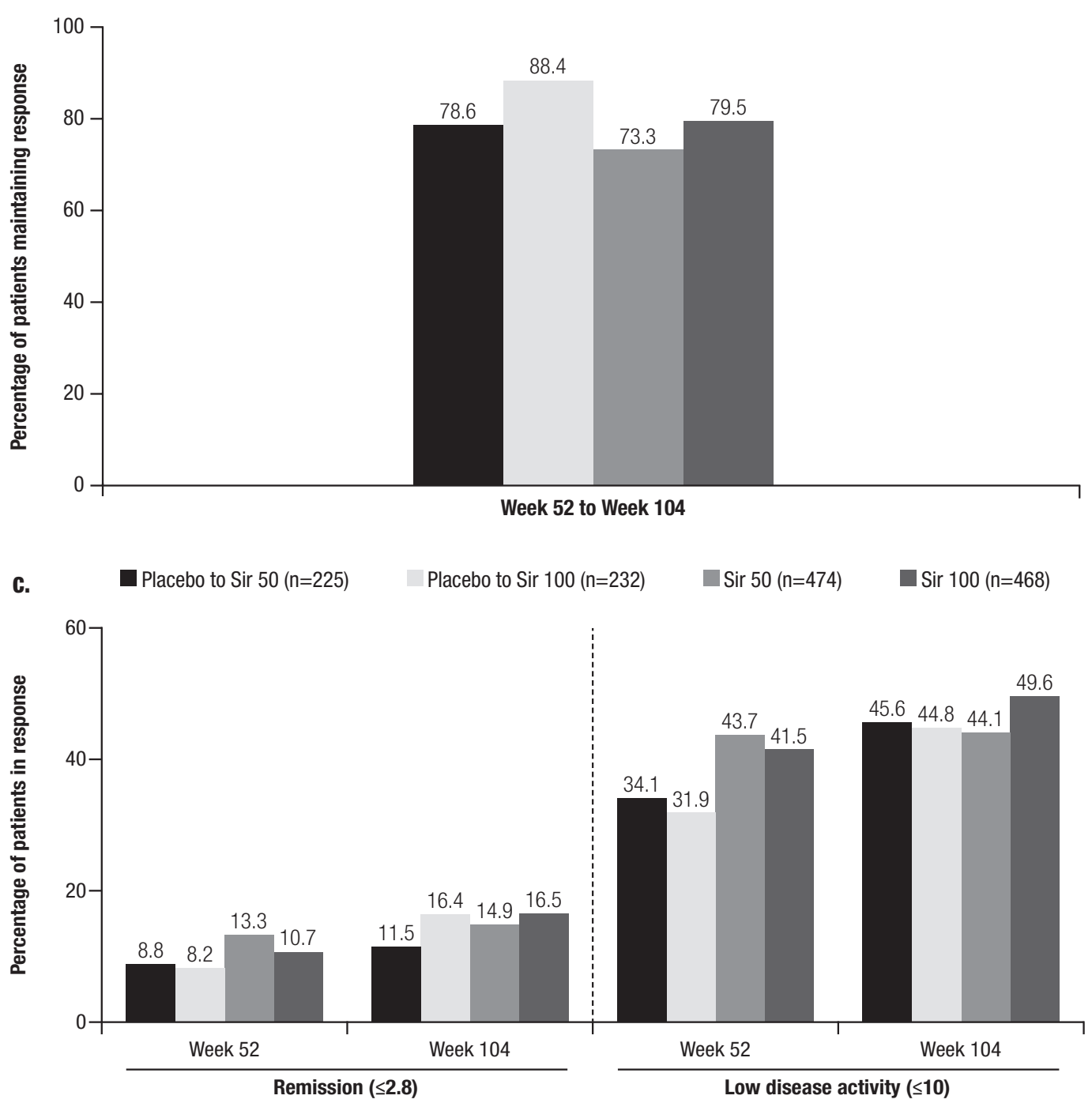

Figure 2 Disease activity measures. Proportions of patients who achieved (A) DAS28 (CRP) <2.6 at Week 52 and Week $104^{*}+$; (B) DAS28 (CRP) <2.6 at Week 52 and sustained through Week 104‡; (C) CDAl remission or low disease activity at Week 52 and Week $104^{*} \S \rrbracket$. *n values shown in legend are the number of patients evaluable at Week 52 . †DAS28 (CRP) <2.6 was based on imputed value by missing data (NR)/TF(NR). ‡DAS28 (CRP) $<2.6$ was based on observed data. §CDAI remission was based on imputed value by missing data (NR)/TF(NR). ПCDAl low disease activity was based on imputed value by missing data (NR)/ TF(NR). CDAI, Clinical Disease Activity Index; CRP, C-reactive protein; DAS28 (CRP), Disease Activity Score in 28 joints based on CRP; NR, non-responder; Sir, sirukumab; TF, treatment failure; q2w, every 2 weeks; q4w, every 4 weeks. 

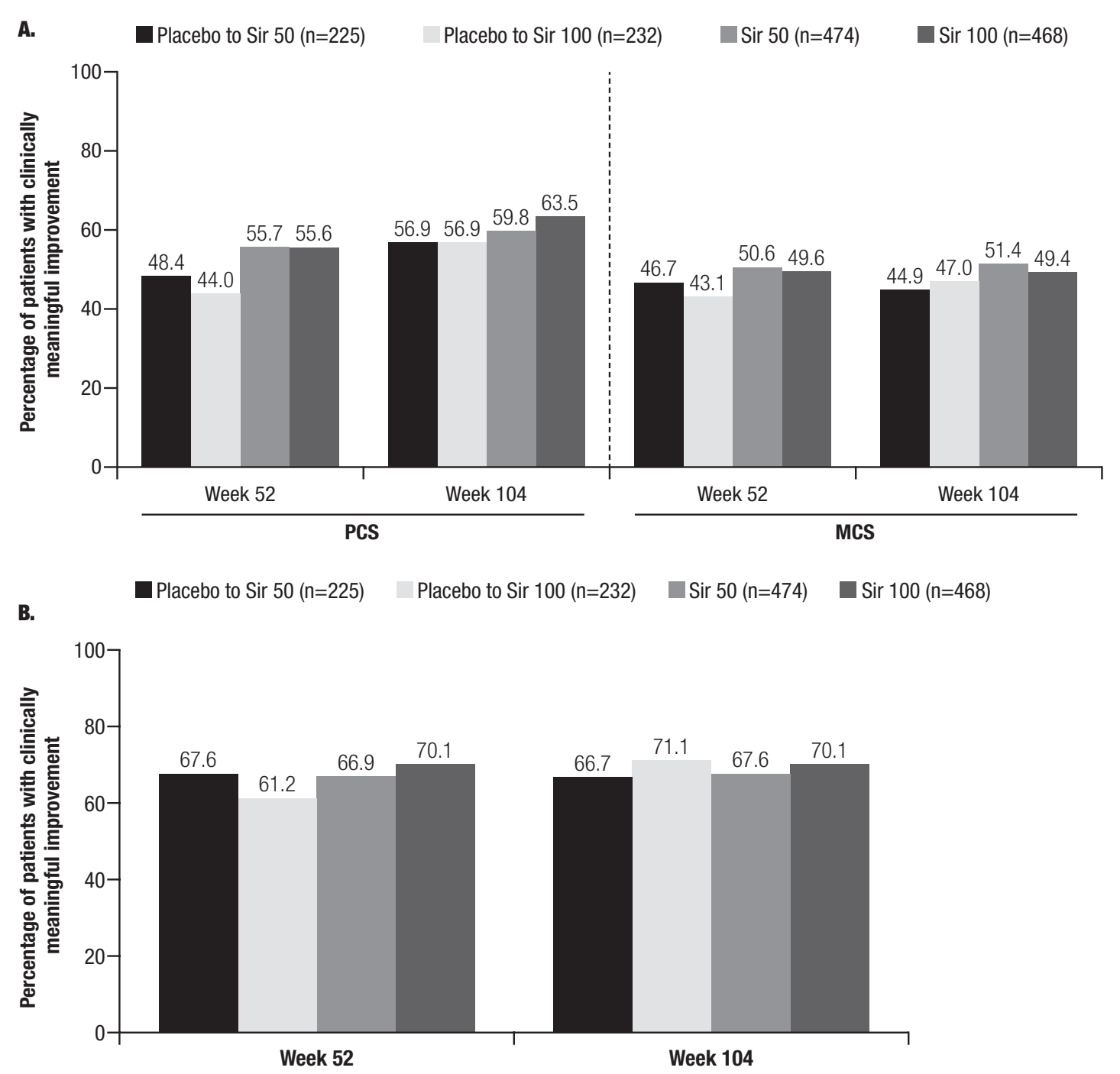

Figure 3 Patient-reported outcomes: proportion of patients with clinically meaningful improvements in (A) SF-36 PCS and MCS at Week 52 and Week $104^{*} \dagger \neq$ and (B) HAQ-DI at Week 52 and Week $104^{*} \S$ ๆ. ${ }^{*} n$ values shown in legend are the number of patients evaluable at Week 52. †A $\geq 5$-point improvement from baseline in PCS and MCS scores was considered a clinically meaningful improvement. $¥$ The SF-36 score was based on imputed value by missing data (LOCF). §A change of -0.22 from baseline in HAQ-DI was considered a clinically meaningful improvement. ๆThe HAQ-DI score was based on imputed value by missing data (LOCF). HAQ-DI, Health Assessment Questionnaire-Disability Index; LOCF, last observation carried forward; MCS, mental component summary; PCS, physical component summary; SF-36, 36-item Short Form Survey; Sir, sirukumab; q2w, every 2 weeks; q4w, every 4 weeks.

was reported. Four of the five patients treated with sirukumab who developed hypersensitivity were tested for antibodies to sirukumab, all yielding negative results. Twenty-one deaths occurred in the sirukumab-treated groups, with no dose effect observed and no time-dependent relationship to sirukumab exposure. The causes of death were as expected for an RA population (table 2).

Infections were the most frequently observed class of SAEs. The overall incidence (per 100 patient years of exposure) of serious infections was 6.01 in the sirukumab $50 \mathrm{mg} \mathrm{q} 4 \mathrm{w}$ combined group and 5.83 in the sirukumab $100 \mathrm{mg} \mathrm{q} 2 \mathrm{w}$ combined group. One case of active pulmonary tuberculosis was reported in the sirukumab $100 \mathrm{mg}$ $\mathrm{q} 2 \mathrm{w}$ group. Two serious opportunistic infections (cytomegalovirus colitis in the sirukumab $50 \mathrm{mg}$ q4w group and fungal eye infection in the sirukumab $100 \mathrm{mg} \mathrm{q} 2 \mathrm{w}$ group) were reported.

Gastrointestinal (GI) perforations are a known consequence of anti-IL-6 therapy and the events reported in this trial are consistent with events seen with other antiIL-6 agents. Through Week 120, a total of five GI perforations (one in the placebo group, three in the sirukumab $50 \mathrm{mg} \mathrm{q} 4 \mathrm{w}$ combined group and one in the sirukumab $100 \mathrm{mg} \mathrm{q} 2 \mathrm{w}$ combined group) were reported. Of the five GI perforations, one was an upper GI perforation and four were lower GI perforations. The overall incidence (per 100 patient years of exposure) of GI perforation was low, with 0.24 in the sirukumab $50 \mathrm{mg} \mathrm{q} 4 \mathrm{w}$ combined group and 0.08 in the sirukumab $100 \mathrm{mg} \mathrm{q} 2 \mathrm{w}$ combined group. 
A.

Placebo to Sir $50(n=203)$

Placebo to Sir $100(n=203)$

Sir $50(n=419)$

Sir $100(n=444)$

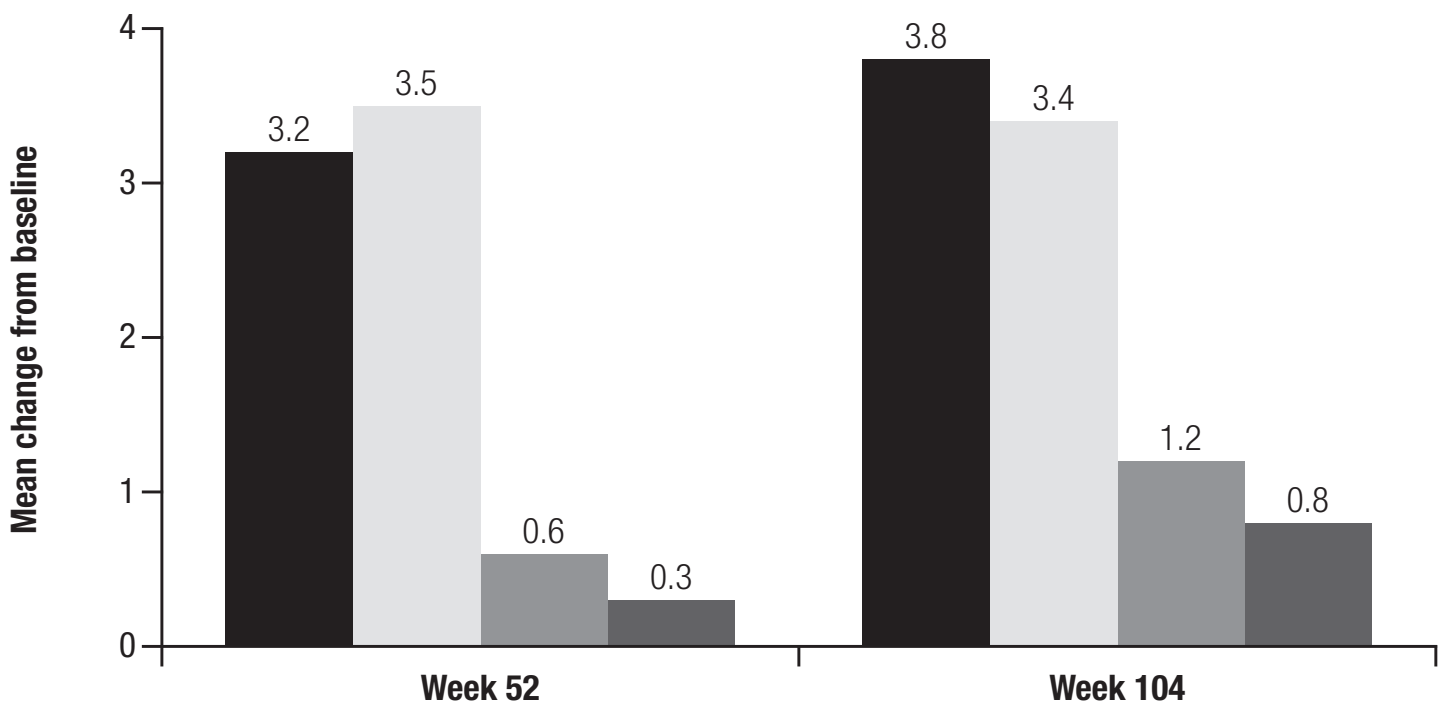

B.

Placebo to Sir 50

Placebo to Sir 100

$\triangle \operatorname{Sir} 50$

$\diamond \operatorname{Sir} 100$
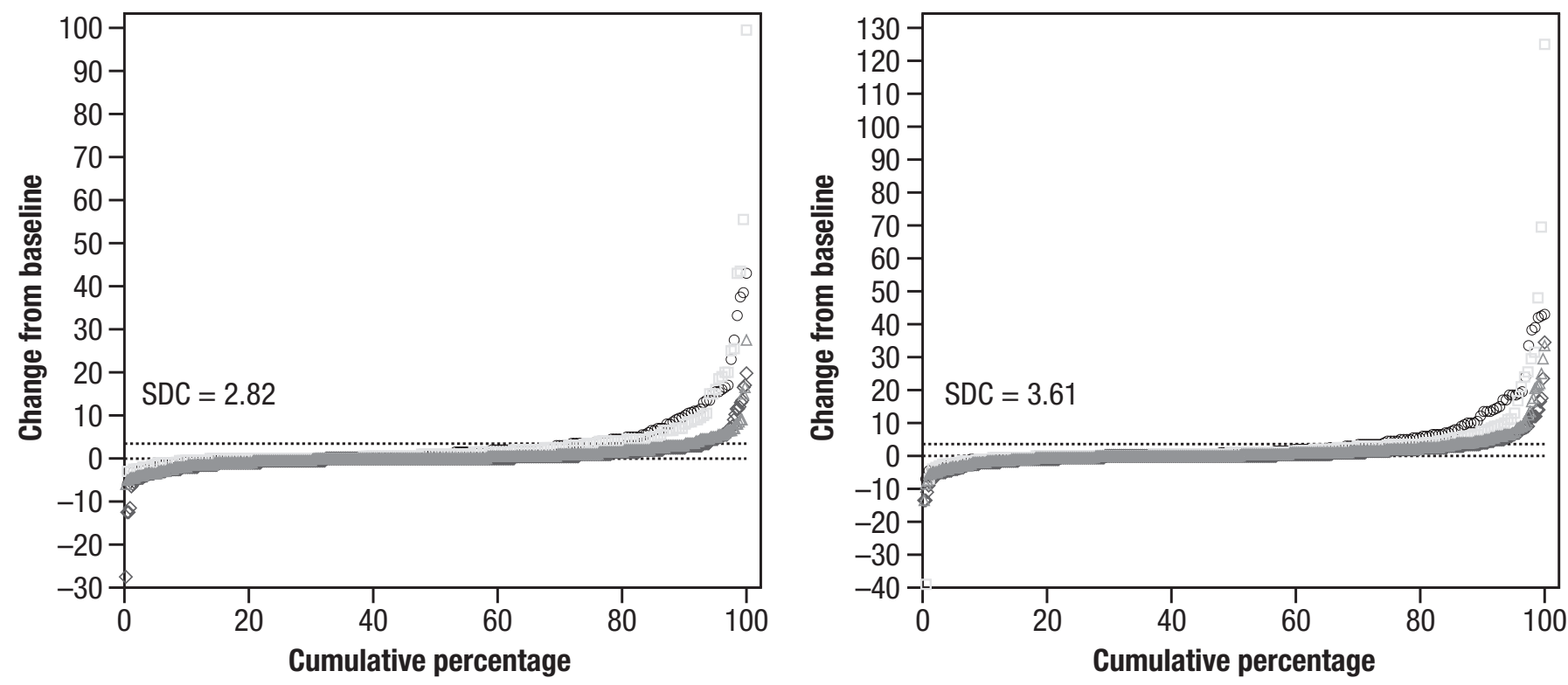

Figure 4 Radiographic endpoints: (A) change from baseline in SHS at Week 52 and Week $104^{*} \dagger$; (B) probability plots of change from baseline in SHS at Week 52 and Week 104. *n values shown in legend are the number of patients evaluable at Week 52. †The SHS was based on observed data from read Campaign 2. CO, crossover; EE, early escape; LE, late escape; SDC, smallest detectable change; SHS, modified Sharp/van der Heijde score; Sir, sirukumab; q2w, every 2 weeks; q4w, every 4 weeks.

Laboratory results showed that the majority of alanine aminotransferase and aspartate aminotransferase elevations were mild and asymptomatic. Increases in total cholesterol, low-density lipoprotein cholesterol, high-density lipoprotein cholesterol and fasting triglycerides were observed and consistent with an increase in lipid parameters associated with anti-IL-6 treatment. The increases in lipid parameters were observed early after treatment with sirukumab; the elevations remained stable, did not continue rising over time and were reversible once sirukumab treatment was stopped.

Laboratory abnormalities with toxicity grades 3 or 4 are summarised in online supplementary table S4. Of the patients evaluable for immunogenicity, 2.4\% (20/835) had antibodies to sirukumab by Week 104, which is the same low incidence that was observed through Week $52 .{ }^{13}$ Of the 20 patients who tested positive for antibodies to sirukumab, 14 were in the sirukumab $50 \mathrm{mg} \mathrm{q} 4 \mathrm{w}$ combined group and six 
Table 2 Overall summary of treatment-emergent AEs through end of study (Week 120* $† \ddagger$

\begin{tabular}{|c|c|c|c|c|}
\hline & \multirow[b]{2}{*}{$\begin{array}{l}\text { Placebo } \\
(\mathrm{n}=556)\end{array}$} & \multicolumn{3}{|l|}{ Sirukumab } \\
\hline & & $\begin{array}{l}50 \mathrm{mg} \mathrm{q4w} \\
(\mathrm{n}=798)\end{array}$ & $\begin{array}{l}100 \mathrm{mg} \text { q2w } \\
(\mathrm{n}=799)\end{array}$ & $\begin{array}{l}\text { Overall } \\
(n=1597)\end{array}$ \\
\hline Mean duration of follow-up (weeks) & 37.35 & 83.15 & 83.56 & 83.36 \\
\hline Mean number of study agent administrations, $\mathrm{n}$ & 17.46 & 38.76 & 38.81 & 38.79 \\
\hline Patients with $\geq 1 \mathrm{AEs}$ & $365(65.6)$ & $670(84.0)$ & $693(86.7)$ & $1363(85.3)$ \\
\hline Patients with $\geq 1$ SAEs & $40(7.2)$ & $141(17.7)$ & $132(16.5)$ & $273(17.1)$ \\
\hline $\begin{array}{l}\text { Patients with } \geq 1 \mathrm{AEs} \text { that caused study agent } \\
\text { discontinuation }\end{array}$ & $19(3.4)$ & $89(11.2)$ & $101(12.6)$ & $190(11.9)$ \\
\hline Patients with $\geq 1$ serious infections & $11(2.0)$ & $58(7.3)$ & $47(5.9)$ & $105(6.6)$ \\
\hline Patients with $\geq 1$ injection site reactions & $14(2.5)$ & $84(10.5)$ & $135(16.9)$ & $219(13.7)$ \\
\hline Patients with $\geq 1$ MACE & $1(0.2)$ & $13(1.6)$ & $5(0.6)$ & $18(1.1)$ \\
\hline Patients with $\geq 1$ malignancies & $2(0.4)$ & $8(1.0)$ & $12(1.5)$ & $20(1.3)$ \\
\hline Patients with $\geq 1 \mathrm{Gl}$ perforations & $1(0.2)$ & $3(0.4)$ & $1(0.1)$ & $4(0.3)$ \\
\hline Patients with $\geq 1$ hepatobiliary abnormalities & $3(0.5)$ & $3(0.4)$ & $14(1.8)$ & $17(1.1)$ \\
\hline $\begin{array}{l}\text { Patients with } \geq 1 \text { hypersensitivity reaction or } \\
\text { serum sickness } A E\end{array}$ & $2(0.4)$ & $2(0.3)$ & $3(0.4)$ & $5(0.3)$ \\
\hline Patients with $\geq 1$ opportunistic infections & 0 & $1(0.1)$ & $4(0.5)$ & $5(0.3)$ \\
\hline Patients who died during the study§ & $1(0.2)$ & $10(1.3)$ & $11(1.4)$ & $21(1.3)$ \\
\hline \multicolumn{5}{|c|}{ Events of $\geq 5 \%$ frequency in any sirukumab group, $n(\%)$} \\
\hline Alanine aminotransferase increased & $24(4.3)$ & $145(18.2)$ & $171(21.4)$ & $316(19.8)$ \\
\hline Aspartate aminotransferase increased & $18(3.2)$ & $85(10.7)$ & $112(14.0)$ & $197(12.3)$ \\
\hline Upper respiratory tract infection & $63(11.3)$ & $104(13.0)$ & $92(11.5)$ & $196(12.3)$ \\
\hline Nasopharyngitis & $53(9.5)$ & 87 (10.9) & $86(10.8)$ & $173(10.8)$ \\
\hline Injection site erythema & $6(1.1)$ & $61(7.6)$ & $101(12.6)$ & $162(10.1)$ \\
\hline Bronchitis & $28(5.0)$ & $65(8.1)$ & $49(6.1)$ & $114(7.1)$ \\
\hline Rheumatoid arthritis & $40(7.2)$ & $59(7.4)$ & $47(5.9)$ & $106(6.6)$ \\
\hline Hypertension & $22(4.0)$ & $46(5.8)$ & $57(7.1)$ & $103(6.4)$ \\
\hline Leucopaenia & $7(1.3)$ & $50(6.3)$ & $49(6.1)$ & $99(6.2)$ \\
\hline Neutropaenia & $5(0.9)$ & $52(6.5)$ & $45(5.6)$ & $97(6.1)$ \\
\hline Headache & $22(4.0)$ & $46(5.8)$ & $38(4.8)$ & $84(5.3)$ \\
\hline Urinary tract infection & $13(2.3)$ & $40(5.0)$ & $40(5.0)$ & $80(5.0)$ \\
\hline Injection site pruritus & $1(0.2)$ & $15(1.9)$ & $48(6.0)$ & $63(3.9)$ \\
\hline Injection site swelling & 0 & $18(2.3)$ & $40(5.0)$ & $58(3.6)$ \\
\hline
\end{tabular}

${ }^{*}$ All values are $\mathrm{n}(\%)$ unless otherwise noted. Data are cumulative across all phases of the study (blinded placebo-controlled (Week 0 to Week 52), blinded active treatment (Week 52 to Week 104) and safety follow-up (Week 104 to Week 120)).

†Patients may appear in more than one column.

‡Based on all patients who received at least one (partial or complete) dose of sirukumab through Week 120.

$\S$ Eleven patients died from Week 0 to Week 52 as reported previously. ${ }^{13}$ Ten patients died from Week 52 to Week 104: one patient who was randomised to placebo and rerandomised (EE) to sirukumab $100 \mathrm{mg}$ q2w experienced sudden severe chest pain and died; four patients randomised to placebo and rerandomised to sirukumab $100 \mathrm{mg} \mathrm{q} 2 \mathrm{w}$ at Week 52: one died from sepsis of urinary origin, one from cardiorespiratory arrest due to community-acquired pneumonia, one from gastric cancer and one from aortic dissection; two patients randomised to placebo and rerandomised to sirukumab $50 \mathrm{mg} \mathrm{q} 4 \mathrm{w}$ at Week 52 died: one from sepsis and one died after experiencing SAEs of acute myeloid leukaemia, necrotising fasciitis, sepsis and UTI; one patient randomised to sirukumab 50 mg q4w died from respiratory failure.

AE, adverse event; EE, early escape; MACE, major adverse cardiovascular events; SAE, serious adverse event; UTI, urinary tract infection; q2w, every 2 weeks; q4w, every 4 weeks.

were in the sirukumab $100 \mathrm{mg}$ q2w combined group. Only two patients were positive for neutralising antibodies to sirukumab (one each in the sirukumab $50 \mathrm{mg} \mathrm{q} 4 \mathrm{w}$ combined group and the sirukumab $100 \mathrm{mg}$ q2w combined group).

\section{DISCUSSION}

The current report presents the full, 2-year efficacy and safety results from the SIRROUND-D clinical trial. As reported previously, ${ }^{13}$ this study met its coprimary 
endpoints (ACR20 response at Week 16 and change from baseline in SHS score at Week 52), and all major secondary endpoints, including change from baseline in HAQ-DI, ACR50 response and DAS28 (CRP) $<2.6$ at Week 24.

The current results demonstrate that sirukumab was efficacious in inhibiting radiographic progression, reducing signs and symptoms of RA and improving overall function in patients with moderately to severely active RA. The sirukumab dose regimens of $50 \mathrm{mg} \mathrm{q} 4 \mathrm{w}$ and $100 \mathrm{mg} \mathrm{q} 2 \mathrm{w}$ exhibited similar long-term efficacy, consistent with findings that these two dose regimens appear to be on the plateau portion of the dose-response curve. ${ }^{14}$ The effects observed after 1 year of sirukumab treatment are enduring-in some cases, improved-after an additional 12 months of treatment. The clinically relevant effects in the original active treatment groups were maintained and patients who crossed over from placebo to active treatment also achieved improvements in clinical parameters from Week 52 to Week 104 that matched those in groups randomised to sirukumab from study initiation. Additionally, the overall safety profile of sirukumab did not show any new safety signals in the extended 2-year exposure period.

Inhibition of radiographic progression at Week 52 was maintained through Week 104 based on observed data from Read Campaign 2 in patients originally randomised to sirukumab or who switched from placebo to sirukumab at Weeks 18 (EE)/40 (LE)/52 (crossover). Patients treated with sirukumab $50 \mathrm{mg} \mathrm{q} 4 \mathrm{w}$ and $100 \mathrm{mg}$ $q 2 w$ showed less change from baseline in erosion and JSN scores compared with patients in the placebo crossover groups at Week 52 and Week 104. The proportion of patients with no radiographic progression (a change of $\leq 0$ from baseline in SHS score) was similar from Week 52 to Week 104 in the placebo crossover groups and groups originally randomised to sirukumab.

A recent large study $(\mathrm{N}=885)$ examined the long-term treatment efficacy of another anti-IL-6 agent, tocilizumab, in patients refractory to DMARD therapy. Results demonstrated clinical improvements in patients with up to two previous DMARD failures, with favourable results observed by 6 months of treatment, which endured beyond 3 years. ${ }^{15}$ Another anti-IL- 6 agent, sarilumab, was demonstrated to achieve clinical success in patients with RA over the course of 1 year of treatment; however, long-term studies are needed to evaluate the durability of those effects. ${ }^{16}$

The long duration of this study, high enrolment and retention over the course of the trial, and large, comprehensive battery of clinical and radiological assessments used, all contributed to the significant strength of this study. In addition, approximately one-third of patients had previously received biological DMARDs and two-thirds had previously received treatment with two or more conventional DMARDs, which is an accurate reflection of the emerging patient population with RA. Weaknesses of the study included the fact that the study population was limited to patients refractory to DMARDs and thus may not represent the full spectrum of patients with RA. Additionally, the study design by which all patients were crossed over into active treatment at Week 52 forfeited the placebo control component for the second year. The SIRROUND-D study design removes the control group from the long-term efficacy analyses and confounds the long-term safety analyses. This occurs by progressively eroding the randomised placebo control group of patients through the transition of these patients into the sirukumab treatment groups at EE, LE and last, crossover visits. By the second year of this 2-year study, all 1597 patients were being treated with sirukumab. This progressive loss of randomised groups especially complicates the interpretation of higher rates of occurrence of events that occur infrequently or with latency (eg, major adverse cardiovascular events, malignancies or all-cause mortality) in sirukumab-treated patients compared with placebo patients.

In conclusion, treatment with sirukumab resulted in minimal progression in radiographic damage over 2 years and thus inhibition of joint damage demonstrated at Week 52 was maintained through Week 104. Active treatment provided reduction in clinical signs and symptoms of RA and improvements in physical function and patient-reported outcomes that were maintained through Week 104. The safety profile of sirukumab was as expected for an anti-IL-6 agent, with no new signals reported.

\section{Author affiliations}

${ }^{1}$ Janssen Research \& Development, LLC, Spring House, Pennsylvania, USA ${ }^{2}$ University of Toronto and Southlake Regional Health Centre, Newmarket, Ontario, Canada

${ }^{3}$ Division of Rheumatology, Keio University School of Medicine, Tokyo, Japan ${ }^{4}$ Division of Rheumatology, Harbor-UCLA Medical Center, Torrance, California, USA ${ }^{5}$ GlaxoSmithKline, Collegeville, Pennsylvania, USA

Contributors CT, TT, GAK, SS, RK and BH contributed to the study design. TT and KF contributed to patient recruitment and treatment. TT, GAK, KF and BH contributed to the conduct of the study. SS and KF collected data. CT, GAK, SS and $\mathrm{KF}$ analysed data. All authors interpreted the data, contributed to drafting the work or revising it critically for important intellectual content, provided final approval of the version published and agreed to be accountable for all aspects of the work.

Funding This study was sponsored by Janssen Research \& Development, LLC, in collaboration with GlaxoSmithKline. Writing and editorial support were provided by Allison Michaelis, PhD, of MedErgy, and were funded by Janssen Global Services, LLC and GlaxoSmithKline.

Competing interests CT: grant/research support from Celgene, Novartis and Pfizer; advisory board and consultant for AbbVie, Amgen, Celgene, Hospira, Lilly, Novartis and Pfizer; steering committee for Janssen/Centocor/Johnson \& Johnson. TT: grant/research support from Astellas Pharma, Bristol-Myers K.K., Chugai Pharmaceutical Co., Ltd., Daiichi Sankyo Co., Ltd., Eisai Co., Ltd., Mitsubishi Tanabe Pharma Co., Pfizer Japan Inc., Santen Pharmaceutical Co., Ltd., Takeda Pharmaceutical Co., Ltd., Teijin Pharma, Ltd., AbbVie GK, Asahi Kasei Pharma Corp., Taisho Toyama Pharmaceutical Co., Ltd. and SymBio Pharmaceuticals Ltd; consultant for AstraZeneca K.K., Eli Lilly Japan K.K., Novartis Pharma K.K., Mitsubishi Tanabe Pharma Co., Asahi Kasei Medical K.K., AbbVie GK, Daiichi Sankyo Co., Ltd., Bristol-Myers K.K. and Nipponkayaku Co., Ltd.; speakers bureau for AbbVie GK., Bristol-Myers K.K., Chugai Pharmaceutical Co., Ltd., Eisai Co., Ltd., Janssen Pharmaceutical K.K., Mitsubishi Tanabe Pharma Co., Pfizer Japan Inc., Takeda Pharmaceutical Co., Ltd., Astellas Pharma, Daiichi Sankyo Co., Ltd., Celtrion and Nipponkayaku Co., Ltd. GAK: grant/research support from Pfizer; consultant for Bristol-Myers Squibb, Genentech, GlaxoSmithKline, Janssen, Pfizer, Regeneron, Roche and Sanofi; speakers bureau for Bristol-Myers Squibb, Genentech, GlaxoSmithKline, Janssen, Pfizer, Regeneron, Roche and Sanofi. SS, KF, BH: employees and shareholders of Janssen Research \& Development, LLC. RK: Employee and shareholder of GlaxoSmithKline.

Patient consent Not required. 
Ethics approval The study protocol was approved by the relevant institutional review boards or ethics committees at each study site.

Provenance and peer review Not commissioned; externally peer reviewed.

Data sharing statement The data sharing policy of Janssen Pharmaceutical Companies of Johnson \& Johnson is available at https://www.janssen.com/clinicaltrials/transparency. As noted on this site, requests for access to the study data can be submitted through Yale Open Data Access (YODA) Project site at http://yoda. yale.edu.

Open access This is an open access article distributed in accordance with the Creative Commons Attribution Non Commercial (CC BY-NC 4.0) license, which permits others to distribute, remix, adapt, build upon this work non-commercially, and license their derivative works on different terms, provided the original work is properly cited, appropriate credit is given, any changes made indicated, and the use is non-commercial. See: http://creativecommons.org/licenses/by-nc/4.0/.

\section{REFERENCES}

1. Kishimoto T. Interleukin-6: from basic science to medicine-40 years in immunology. Annu Rev Immunol 2005;23:1-21.

2. Hunter CA, Jones SA. IL-6 as a keystone cytokine in health and disease. Nat Immunol 2015;16:448-57.

3. Arend WP, Dayer JM. Cytokines and cytokine inhibitors or antagonists in rheumatoid arthritis. Arthritis Rheum 1990;33:305-15.

4. Mclnnes IB, Schett G. Pathogenetic insights from the treatment of rheumatoid arthritis. Lancet 2017;389:2328-37.

5. Flannery CR, Little CB, Hughes CE, et al. IL-6 and its soluble receptor augment aggrecanase-mediated proteoglycan catabolism in articular cartilage. Matrix Biol 2000;19:549-53.

6. Lipsky PE. Interleukin-6 and rheumatic diseases. Arthritis Res Ther 2006;8(Suppl 2):S4

7. Ishihara K, Hirano T. IL-6 in autoimmune disease and chronic inflammatory proliferative disease. Cytokine Growth Factor Rev 2002;13:357-68.
8. Kremer J, Fleischmann R, Brzezicki J. Tocilizumab inhibits structural joint damage, improves physical function, and increases DAS28 remission rates in RA patients who respond inadequately to methotrexate: the Lithe study. Ann Rheum Dis 2009;68(Suppl 3):122.

9. Emery P, Keystone E, Tony HP, et al. IL-6 receptor inhibition with tocilizumab improves treatment outcomes in patients with rheumatoid arthritis refractory to anti-tumour necrosis factor biologicals: results from a 24-week multicentre randomised placebocontrolled trial. Ann Rheum Dis 2008;67:1516-23.

10. Jones G, Sebba A, Gu J, et al. Comparison of tocilizumab monotherapy versus methotrexate monotherapy in patients with moderate to severe rheumatoid arthritis: the AMBITION study. Ann Rheum Dis 2010;69:88-96.

11. Nishimoto N, Hashimoto J, Miyasaka N, et al. Study of active controlled monotherapy used for rheumatoid arthritis, an IL-6 inhibitor (SAMURAI): evidence of clinical and radiographic benefit from an $\mathrm{x}$ ray reader-blinded randomised controlled trial of tocilizumab. Ann Rheum Dis 2007;66:1162-7.

12. Smolen JS, Beaulieu A, Rubbert-Roth A, et al. Effect of interleukin-6 receptor inhibition with tocilizumab in patients with rheumatoid arthritis (OPTION study): a double-blind, placebo-controlled, randomised trial. Lancet 2008;371:987-97.

13. Takeuchi T, Thorne C, Karpouzas G, et al. Sirukumab for rheumatoid arthritis: the phase III SIRROUND-D study. Ann Rheum Dis 2017;76:2001-8.

14. $\mathrm{Xu} \mathrm{Y}, \mathrm{Hu} \mathrm{C}$, Zhuang $\mathrm{Y}$, et al. Exposure-response modeling analyses for sirukumab, a human monoclonal antibody targeting interleukin 6 in patients with moderately to severely active rheumatoid arthritis. $J$ Clin Pharmacol 2018;58:1501-15.

15. Baganz L, Richter A, Kekow J, et al. Long-term effectiveness of tocilizumab in patients with rheumatoid arthritis, stratified by number of previous treatment failures with biologic agents: results from the German RABBIT cohort. Rheumatol Int 2018;38:579-87.

16. Aly AM, Furst DE. Update of sarilumab to treat rheumatoid arthritis based on randomized clinical trials: a systematic review. Expert Rev Clin Immunol 2017;13:741-52. 